\title{
Interpretation of Compressibility Properties of Soil Surrounding Bored Piles from Pile Load Test Results
}

\author{
H. S. Thilakasiri and W. H. Silva
}

\begin{abstract}
Unsatisfactory bored pile may result due to low skin frictional resistance or due to low end bearing resistance. A new methodology is proposed herein to estimate the shear stiffness of the material along the pile shaft using the static load - settlement curve. The stiffness, estimated in terms of the Young's modulus, of the material along the pile shaft is an indication of the amount of ultimate skin friction. The new methodology, in combination with the earlier method proposed by Thilakasiri and Silva [6] to estimate the Young's modulus of the material below the pile bottom, can be effectively used in interpretation of static load settlement curves to determine the type of the material along the pile shaft and that of the material below the pile bottom. The developed methodology is implemented for static load-settlement curves obtained from testing of bored piles and the advantages of the new methodology are demonstrated.
\end{abstract}

Keywords: Bored piles, Compressibility, Modulus

\section{Introduction}

Cast in-situ bored piles are constructed by creating a borehole in the ground by drilling and subsequently filling it with concrete. During the drilling process bentonite slurry is used to stabilize the sides of the borehole with or without steel casings. The concreting is carried out from the ground surface using a tremie pipe and systematically bentonite is replaced by concrete during the concreting process. However, if the slurry full of hole is kept for a long period of time, a thicker and harder "cake" will be formed and replacement of the slurry with concrete will be difficult resulting in a layer of bentonite slurry between the wall of the hole and the fresh concrete. This layer of bentonite, invariably will reduce the development of skin friction between the soil and the concrete.

In the design of such piles, it is a common practice to neglect the skin friction resistance, mainly due to the presence of bentonite in the borehole during concreting, and design of such piles is entirely based on the possible end bearing from the bedrock. In the local design practice, the bored piles should be socketed to a minimum of $300 \mathrm{~mm}$ into the bedrock. However, based on the results of static and dynamic load tests, Thilakasiri [4] showed that there is reasonable skin frictional resistance developed in bored and cast in-situ concrete piles constructed in Sri Lanka.
Carrying capacity of cast in-situ concrete piles may be reduced due to two main reasons: (i) False identification of the bedrock or improper cleaning of the borehole resulting in low end bearing capacity; and (ii) Presence of a thick layer of bentonite between the pile and the surrounding soil due to formation of a hard filter cake resulting in low skin frictional capacity. The weathered rock layer consists of different type of material depending on the degree of weathering and the type of the parent rock. At most locations, the transition from highly decomposed rock to the sound bedrock is gradual and there is no definite demarcation between the weathered rock and the bedrock. Due to this reason, the geotechnical engineers are faced with the problem of identification of the so called 'bedrock' and socketing the pile $300 \mathrm{~mm}$ into the bedrock. Thilakasiri and Silva [6] proposed a new methodology to investigate the end bearing condition of cast in-situ concrete piles based on static load test results. However, there is no proper method to investigate the shear stiffness of the surrounding soil and hence the skin friction provided by the same.

The objectives of this research paper could be summarised as follows:

Eng. (Dr.) H. S. Thilakasiri, C. Eng., PEng.(SL), MIE(SL),B.Sc. En (Hons)(Moratuwa),M.Sc. (London), PhD(USA), Senior Lecturer in Civil Engineering, Department of Civil Engineering, University of Moratuwa, Sri Lanka.

W H Silva, Research Assistant, Department of Civil Engineering, University of Moratuwa, Sri Lanka. 
- Introducing a new methodology to investigate the stiffness of the soil surrounding the pile shaft;

- Hence, the separation of the load acting on the pile during initial stage of the loading into skin friction and end bearing components; and

- Application of the new methodology to rock socketed bored piles in Sri Lanka to investigate the end bearing condition of such piles.

\section{Determination of the Compressibility Parameters of the Material Surrounding the pile from Static Load Test Results}

\subsection{Material Present at the Pile Toe}

Thilakasiri and Silva [6] investigated the loadsettlement behavior of bored piles and proposed a methodology to obtain the Young's modulus of the material present at the pile toe. According to Van Weele [8], when a pile is loaded, initially the load is carried mostly by skin friction until the shaft deformation is sufficient to mobilize the limiting value, as shown in the region $o a$ in Figure 1. When the limiting skin friction is mobilized, the point load increases nearly linearly until the ultimate end bearing capacity is reached, as shown by region $a b$ of Figure 1. At the point of the ultimate end bearing, the pile undergoes large settlement under a relatively small load increment. However, it should be noted that the load settlement curve from the static load test could deviate from the shape shown in Figure 2 due to unusual subsurface conditions and defective pile shaft. Moreover, depending on the magnitude of the applied load and the ultimate skin frictional resistance, for some piles ultimate skin frictional resistance may not be mobilized. For such piles, the region $a b$, shown in Figure 1, may not be visible.

Once the skin friction has reached the ultimate value, $P_{\text {skin }}$ further increment of skin frictional resistance is not possible. Therefore, any increment in the load on the pile head $(\Delta p)$, after reaching ultimate skin friction, will be equal to the change in the end bearing load $\left(\Delta P_{\text {end }}\right)$. Therefore, it could be proved that the Young's modulus $\left(E_{b}\right)$ of the material below the pile toe can be expressed as equation [1] (Tomlinson [7]):
$E_{b}=\frac{\pi B\left(1-v^{2}\right) I_{p}}{4 A\left(\frac{\Delta \rho}{\Delta P}-\frac{L}{A E_{p}}\right)}$

Where $B$ - Width of the pile base

$L$ - Length of the pile

$A$ - Cross sectional area of the pile shaft

$v$ - Poisson ratio of material at the toe

$E p$ - Young's modulus of the pile material

$\Delta \rho$ - Settlement of the pile head corresponding to the load increment $\Delta \mathrm{P}$ within $a b$ of Figure 1

$I_{P}$ - Settlement influence factor Tomlinson [7]

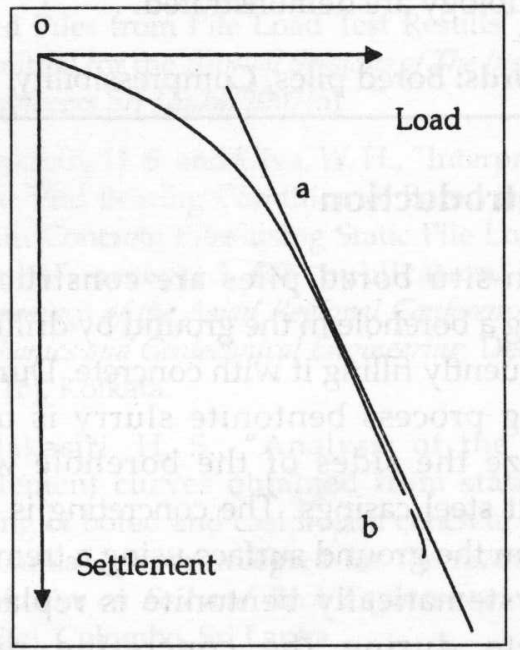

Figure 1: Load settlement curve and the range $a b$, after mobilization of the ultimate skin friction.

If the skin friction has reached the ultimate condition equation [1] could be used to estimate the Young's modulus of the material beneath the toe of a pile. It should be noted here that the Young's modulus $\left(E_{b}\right)$ depends on the strain level due to the highly non-linear nature of soil and rock. However, the settlement required at the pile toe to develop ultimate skin frictional resistance is generally in the order of 2 to $5 \mathrm{~mm}$ (Thilakasiri et al. [5]). As a result, the strain level of the material at the pile toe, when ultimate skin friction is mobilized, is relatively low. Therefore, if the $\Delta \rho$ and $\Delta \rho$ used in Equation [1] are obtained closer to the point " $a$ " in Figure 1, estimated deformation modulus is corresponding to low strain levels.

\subsection{Material Present along the Pile Shaft}

Various theoretical methods were introduced by different researchers to estimate the settlement 
of end bearing bored piles. Most of the theoretical approaches in settlement estimation uses idealized linear elastic medium surrounding the pile. As it is commonly known, soil exhibits a highly nonlinear behavior, especially when subjected to large strain levels. Therefore, applicability of such theoretical methods is limited only to initial loading stage of the pile. One such widely used method is proposed by Poulos [3] and in this method the load $(P)$ applied on the pile top is related to pile top settlement $(\rho)$ through Equations [2] and [3].

$\rho=\frac{P I}{E_{s} D}$

Where

$I=I_{0} R_{k} R_{v} R_{b}$

$E_{s}$ - Young's modulus of soil along the pile shaft

$D$ - Diameter of the pile shaft

$I_{0}$ - Settlement influence factor for incompressible pile in a semi-infinite elastic half-space with a poisson's ratio of 0.5

$R_{k}$ - Modification factor for compressibility of the pile

$R_{v}$ - Modification factor for the poisson's ratio

$R_{b}$ - Modification factor that depends on the ratio $E_{b}, E_{s}$ and $k$.

The relative stiffness factor $k$, which is defined for the solid piles as the ratio between the Young's modulus of the pile material $\left(E_{p}\right)$ and that of the soil along the pile shaft $\left(E_{s}\right)$, is the main parameter that determines the modification factors. In addition, the ratio between the Young's modulus of the end bearing layer $\left(E_{b}\right)$ and the average Young's modulus of the soil along the pile shaft $\left(E_{s}\right)$ is used in estimation of the modification factor $R_{b}$.

Load - settlement curves obtained from static load settlement curves often show a linear portion at the initial stage of loading as shown in Figure 2. Two regions shown in Figure 1: oa and $a b$ are clearly visible in most of the loadsettlement curves obtained from static load testing of bored piles.

It is clear from the Equations [2] and [3] that the settlement of the pile head depends on the Young's modulus of pile material (concrete), diameter and length of the pile, Young's modulus of the material present along the pile shaft, Young's modulus of the material present below the pile toe and the Poisson ratio of the material present along the pile shaft. Out of the above parameters, Young's modulus of the material present below the pile toe was obtained from the method proposed by Thilakasiri and Silva [6]. Young's modulus of the concrete is taken as $35 \mathrm{GPa}$. The Poisson ratio of the soil varies between 0.2 for loose sand to about 0.45 for saturated clay (Poulos and Davis [2]).

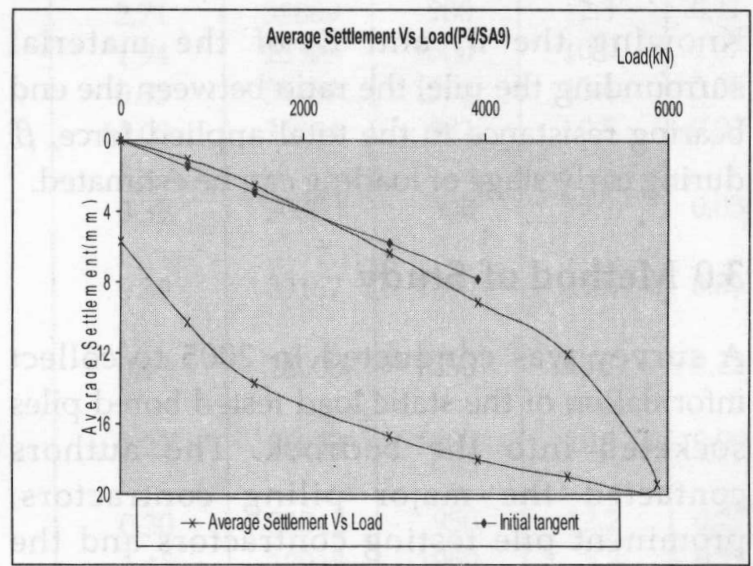

Figure 2. Load - settlement curve showing the initial straight line portion

The weighted average of the Poisson's ratio based on the thickness of the layer, observed in the nearest borehole, is taken as the Poisson ratio for estimation of the settlement. The only other unknown parameter, the Young's modulus of the material present along the pile shaft $(E)$, is varied to match the initial straight line portion of the load-settlement curve as shown in Figure 2. The Es value, which gives the load-settlement behaviour, closest to the initial linear portion of the observed load-settlement curve, is taken as the average Young's modulus value of the soil along the pile shaft.

\subsection{Development of Skin Friction and End Bearing During Initial Stage of the Loading}

Poulos and Davis [2] presented a methodology to separate the magnitude of the SF and end bearing under the low strain condition of the surrounding soils. Poulos and Davis [2] showed that the parameter $\beta$, defined as the ratio between the end bearing resistance to the total applied force during early stage of loading, can be mathematically represented by equation [4] 
$\beta=\beta_{o} C_{v} C_{k} C_{b}$

Where

$\beta_{\mathrm{o}}$ - Parameter that depends on the length and diameter of the pile.

$C_{v}$ - Parameter that depends on the Poisson ratio of the soil along the pile shaft.

$C_{k}$ - Parameter that depends on the relative stiffness $k$, of the pile.

$C_{\mathrm{b}}$ - Parameter that depends on the ratio $E_{b} / E_{s}$ and $k$.

Knowing the $E_{b}$ and $E_{s}$ of the material surrounding the pile, the ratio between the end bearing resistance to the total applied force, $\beta$, during early stage of loading can be estimated.

\subsection{Method of Study}

A survey was conducted in 2005 to collect information of the static load tested bored piles socketed into the bedrock. The authors contacted the major piling contractors, prominent pile testing contractors and the relevant clients to obtain the pile load settlement data of piles from different parts of Sri Lanka. More than $75 \%$ of the organizations contacted by the authors were generous in giving the requested information Authors would like to express their gratitude to the organizations and individuals for making their data available to this study for further improvement of piling practices in Sri Lanka. During the survey, load-settlement curve, details of the pile and, subsurface information were also collected of the tested piles.

Data gathered for 40 such piles were analyzed using the methodology proposed in this paper and the methodology proposed in Thilakasiri and Silva [6].

\subsection{Results and Discussion}

\subsection{Results}

Two methods were used to estimate the Y'oung's modulus of the material present along the pile shaft and at the pile toe. The details of the piles and the Young's modulus of the material at the toe of the piles and along the pile shafts are given in Table 1.
Rock types and the status of the upper part of the rock, obtained from borehole investigation, for different projects are given in Table 2 .

The results are shown in graphical format in Figures 3 and 4 . Figure 3 shows the variation between the Young's modulus value at the pile toe $\left(E_{b}\right)$ and the residual settlement of the pile top after complete unloading. Figure 4 shows the variation of the Young's modulus along the pile shaft $\left(E_{s}\right)$ and the residual settlement after complete unloading.

It is evident from the information given in Table 1 and Figure 3 that piles having high residual settlement after complete unloading have a lower Young's modulus value of the pile toe material. Similarly, Figure 4 shows that the piles having lower $\mathrm{E}_{\mathrm{s}}$ values undergo large residual settlement but there is considerable number of piles with lower $\mathrm{E}_{\mathrm{s}}$ values with lower settlement as well (Pile ID 8, 10, 14, 15, 16, 23, 31 and 33 in Table 1). But in almost all the above mentioned piles considerably high $E_{b}$ values are observed. When the material along the pile shaft is weak more load will be transferred to the pile toe. However, since the residual settlement will be governed by the stiffness of the material at the pile toe, stiffer material at the pile toe will reduce the residual settlement.

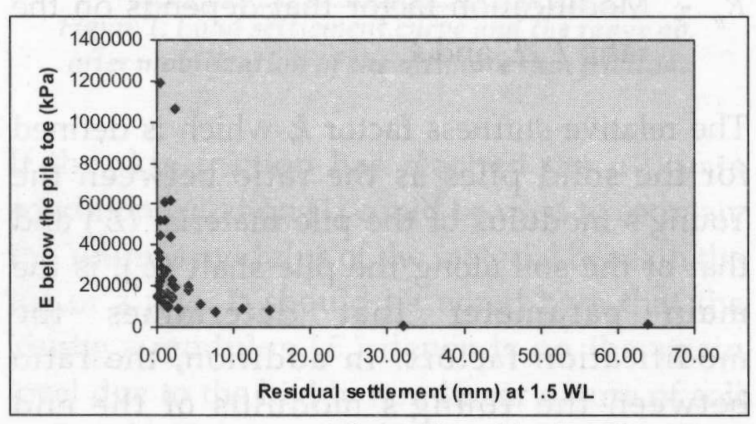

Figure 3: Variation of the $E_{b} V_{s}$ residual settlement

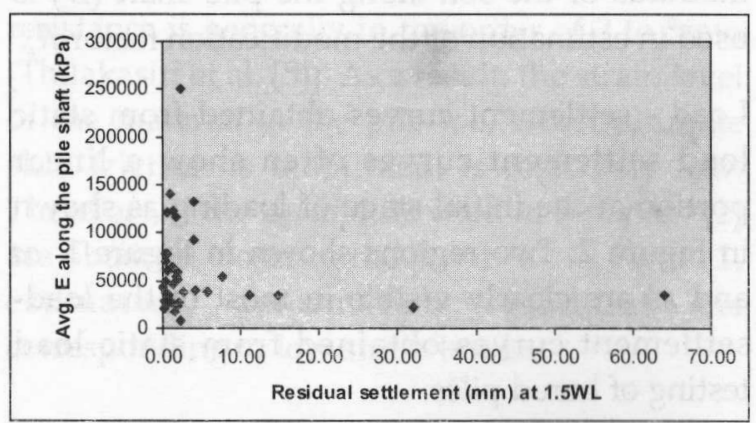

Figure 4: Variation of the $E_{s} V_{s}$ residual settlement 
Table 1: Details of the piles, observed settlement at $1.5 \times$ WL, Net settlement after unloading and the estimated Young's modulus of the material at the pile toe and along the pile shaft

\begin{tabular}{|c|c|c|c|c|c|c|c|c|c|}
\hline $\begin{array}{c}\text { Project } \\
\text { ID }\end{array}$ & Location & $\begin{array}{l}\text { Pile } \\
\text { Length } \\
\text { (m) }\end{array}$ & $\mathrm{Eb}_{\text {(MPa) }}$ & $\begin{array}{c}\text { Total } \\
\text { settlement } \\
(\mathrm{mm}) \text { at } \\
1.5 \times W L\end{array}$ & $\begin{array}{c}\text { Residual } \\
\text { settlement } \\
(\mathrm{mm}) \text { after } \\
\text { unloading }\end{array}$ & Es (MPa) & $\mathbf{K}$ & $\mathrm{Eb} / \mathrm{Es}$ & $\beta$ \\
\hline P1 & Narahenpita & 23.00 & 204.8 & 5.00 & 1.92 & 58333 & 600 & 3.5 & 0.11 \\
\hline P1 & Narahenpita & 23.64 & 618.7 & 4.85 & 1.74 & 53846 & 650 & 11.5 & 0.15 \\
\hline P1 & Narahenpita & 23.11 & 183.0 & 8.23 & 4.01 & 93333 & 375 & 2.0 & 0.06 \\
\hline P1 & Narahenpita & 24.13 & 180.3 & 7.58 & 4.06 & 132075 & 265 & 1.4 & 0.04 \\
\hline $\mathrm{P} 2$ & Battaramulla & 20.45 & 79.0 & 16.90 & 14.70 & 35000 & 1000 & 2.3 & 0.46 \\
\hline P3 & Colombo 10 & 24.60 & 89.4 & 16.00 & 11.81 & 35294 & 992 & 2.5 & 0.03 \\
\hline P3 & Colombo 10 & 6.65 & 151.1 & 6.19 & 1.89 & 51851 & 675 & 2.9 & 0.26 \\
\hline P3 & Colombo 10 & 21.70 & 139.7 & 9.21 & 2.05 & 26923 & 1300 & 5.2 & 0.30 \\
\hline P3 & Colombo 10 & 22.00 & 90.0 & 7.00 & 2.71 & 38889 & 900 & 2.3 & 0.11 \\
\hline P3 & Colombo 10 & 50.65 & 233.2 & 7.32 & 1.94 & 23333 & 1500 & 10.0 & 0.07 \\
\hline P3 & Colombo 10 & 21.35 & 521.7 & 5.25 & 0.33 & 38889 & 1500 & 13.4 & 0.35 \\
\hline P4 & $\begin{array}{l}\text { Polhengoda, } \\
\text { Kirulapone }\end{array}$ & 22.00 & 18.1 & 73.00 & 64.00 & 35294 & 992 & 0.5 & 0.03 \\
\hline P4 & $\begin{array}{l}\text { Polhengoda, } \\
\text { Kirulapone }\end{array}$ & 21.80 & 1194.5 & 4.11 & 0.39 & 70000 & 500 & 17.1 & 0.03 \\
\hline P4 & $\begin{array}{l}\text { Polhengoda, } \\
\text { Kirulapone }\end{array}$ & 18.10 & 334.9 & 5.28 & 0.39 & 29167 & 1200 & 11.5 & 0.34 \\
\hline $\mathrm{P} 4$ & $\begin{array}{l}\text { Polhengoda, } \\
\text { Kirulapone }\end{array}$ & 18.25 & 367.8 & 1.79 & 0.13 & 28000 & 1250 & 13.1 & 0.22 \\
\hline P4 & $\begin{array}{l}\text { Polhengoda, } \\
\text { Kirulapone }\end{array}$ & 19.67 & 272.2 & 6.14 & 1.23 & 26923 & 1300 & 10.1 & 0.09 \\
\hline P5 & Ambatale & 13.89 & 449.9 & 3.58 & 0.30 & 36842 & 950 & 12.2 & 0.27 \\
\hline P5 & Ambatale & 11.79 & 104.8 & 8.23 & 1.45 & 17948 & 1950 & 5.8 & 0.23 \\
\hline P5 & Ambatale & 16.00 & 99.7 & 10.88 & 1.39 & 46667 & 750 & 2.1 & 0.16 \\
\hline P5 & Ambatale & 8.00 & 163.8 & 6.68 & 1.26 & 63636 & 550 & 2.6 & 0.56 \\
\hline P6 & Pettah, Colombo & 14.03 & 256.8 & 7.05 & 0.77 & 35000 & 1000 & 7.3 & 0.40 \\
\hline P6 & Pettah, Colombo & 13.89 & 220.3 & 9.42 & 0.41 & 50000 & 700 & 4.4 & 0.18 \\
\hline P7 & Malabe, Kaduwela & 17.76 & 1065.7 & 7.68 & 2.26 & 7954 & 4400 & 134.0 & 0.33 \\
\hline P8 & Colombo 10 & 14.14 & 166.6 & 3.15 & 1.36 & 122807 & 285 & 1.4 & 0.05 \\
\hline P9 & $\begin{array}{l}\text { Pelawatta, } \\
\text { Battaramulla }\end{array}$ & 10.30 & 146.0 & 9.89 & 0.00 & 43750 & 800 & 3.3 & 0.26 \\
\hline P9 & $\begin{array}{l}\text { Pelawatta, } \\
\text { Battaramulla }\end{array}$ & 11.80 & 166.4 & 4.68 & 0.62 & 60870 & 575 & 2.7 & 0.09 \\
\hline P9 & $\begin{array}{l}\text { Pelawatta, } \\
\text { Battaramulla }\end{array}$ & 13.03 & 237.9 & 2.72 & 0.35 & 77778 & 450 & 3.1 & 0.21 \\
\hline P10 & Sri Jayawardanapura & 8.81 & 525.0 & 2.78 & 1.02 & 140000 & 250 & 3.7 & 0.03 \\
\hline P11 & Galle & 8.54 & 123.4 & 2.15 & 0.65 & 77778 & 450 & 1.6 & 0.06 \\
\hline P11 & Galle & 8.00 & 287.6 & 1.36 & 0.53 & 120970 & 289 & 2.4 & 0.11 \\
\hline P11 & Galle & 6.49 & 142.3 & 1.57 & 0.42 & 23333 & 1500 & 6.1 & 0.46 \\
\hline P11 & Galle & 7.53 & 3.9 & 34.50 & 32.00 & 21875 & 1600 & 0.2 & 0.06 \\
\hline P12 & Narahenpita & 19.43 & 202.9 & 8.25 & 0.19 & 20895 & 1675 & 9.7 & 0.26 \\
\hline P13 & Karapitiya, Gaile & 10.70 & 77.0 & 16.18 & 7.72 & 53846 & 650 & 1.4 & 0.07 \\
\hline P13 & Karapitiya, Galle & 4.00 & 193.8 & 5.85 & 2.29 & 250000 & 140 & 0.8 & 0.09 \\
\hline P14 & Colombo 14 & 26.00 & 200.0 & 14.77 & 4.13 & 40000 & 875 & 5.0 & 0.16 \\
\hline P15 & Colombo 15 & 26.00 & 108.3 & 19.42 & 5.68 & 37838 & 925 & 2.9 & 0.11 \\
\hline P16 & Maligawatta & 11.68 & 284.7 & 5.75 & 0.76 & 30434 & 1150 & 9.4 & 0.33 \\
\hline P17 & Madiwela & 13.77 & 607.7 & 5.61 & 1.06 & 63636 & 550 & 9.5 & 0.33 \\
\hline P18 & Colombo 14 & 19.00 & 441.8 & 3.33 & 1.76 & 116667 & 300 & 3.8 & 0.23 \\
\hline
\end{tabular}

The relative stiffness, $\mathrm{k}$, of the material along the pile shaft falls within 140 to 1675 with an average of 944 , neglecting the pile no 23 , which is installed in very soft overburden material.
Similarly, the ratio between $E_{b}$ and $E_{s}$ varies between 0.8 and 17.1 with an average of 8.6 , when very low values for piles No 12 and 32 are neglected. 
Table 2: General rock types and status of the rock present at the project sites given in Table 1.

\begin{tabular}{|c|l|l|}
\hline Project ID & \multicolumn{1}{|c|}{ Rock type } & \multicolumn{1}{c|}{ Status } \\
\hline P1 & Hornblend Biotite Gneiss & Highly weathered and fractured \\
P2 & Biotite gneiss & $\begin{array}{l}\text { Fresh, contains quartz bands and mica particles } \\
\text { medium weathered, fractured }\end{array}$ \\
P3 & Biotite gneiss & Completely decomposed \\
P4 & Gneiss & \\
P5 & Not available & Fresh, jointed and foliated \\
P6 & Gneiss and Biotite gneiss & \\
P7 & Not available & Fresh, jointed and foliated \\
P8 & Biotite gneiss & Fractured and weathered \\
P9 & Gneiss & \\
P10 & Not available & \\
P11 & Not available & Partially decomposed \\
P12 & Gneiss & Moderately weathered, highly fractures \\
P13 & Gneissic Charnockite & Varies from Fresh to moderately weathered \\
P14 & Biotite gneiss & \\
P15 & Not available & Moderately weathered \\
P16 & Hornblend Biotite Gneiss & \\
P17 & Not available & \\
P19 & Not available & \\
\hline
\end{tabular}

\subsection{Use of the Proposed Methodology in Interpretation of Load-Settlement curves}

\subsubsection{Investigation of the end bearing condition}

The Young's modulus of rock depends on the degree of weathering the material is subjected to, the fracture pattern and spacing. Therefore, a considerable variation in the stiffness of the material at the pile toe could be expected. Moreover, depending on the quality of the construction methodology adopted, even loose debris could be expected at the pile toe of some piles as well. This condition is quite evident from the estimated Young's modulus values, as there is a large variation in the estimated values.

Typical values of Young's modulus for different types of soils and rocks are given in Table 3 . The Young's modulus values given in the Table 3 are obtained from testing the soil or rock in-situ. Therefore, the stiffness is less than that is normally obtained from testing a solid rock specimen in the laboratory.

It is evident from the comparison of the Young's moduli values obtained for the material beneath bored piles and typical values obtained from literature, that the estimated Young's moduli values are not corresponding to those expected for solid bedrock. In residual formations found in Sri Lanka, the bedrock consists of strong rock types such as biotite gneiss, charnockitic gneiss, granite etc. but the upper layers of the bedrock is fractured and partially weathered. Therefore, the Young's modulus of in-situ rock mass could be much less than that obtained from testing fresh solid intact rocks. Comparison of the Estimated Young's modulus of the material below the pile toe given in Table 1 and those obtained from laboratory testing of some rocks found in Sri Lanka given in Table 3 (Jayawardane [1]) clearly shows that the material present below the pile toe is soft. The main reason for such difference could be due to:

i. Possibility of the presence of loose debris at the toe of the pile;

ii. Weathered and fractured nature of the bedrock; and

iii. The small strain level of the ultrasonic method used in the testing to obtain the Young's modulus.

ICTAD/DEV/16 on Specifications for Bored and Cast in-situ Reinforced Concrete Piles specifies that if the pile undergoes more than $12 \mathrm{~mm}$ residual settlement, when loaded upto 1.5 times the working load, the pile should be considered as unsatisfactory. According to that guideline, there are four piles, which undergo more than $12 \mathrm{~mm}$ residual settlement. Out of these four piles, two piles have very low $E_{b}$ values indicative of very loose end bearing conditions or a void. Furthermore, the ratio between $E_{b}$ and $E_{s}$ for these two piles is also very low. The other two piles have $E_{b}$ values 
corresponding to medium dense sand and that could be due to collapsing of the sides into the bored hole before concreting or the false identification of the competent bedrock.

Another important factor to note here is the variability of the Young's modulus values of the material present below the piles from the same project. Variation of the $E_{b}$ for $\mathrm{P} 4$ is $1194.5 \mathrm{MPa}$ to 18.1 MPa whereas that for P11 is $287.6 \mathrm{MPa}$ to 3.9 $\mathrm{MPa}$. The main reasons for such large variations could be due to: variability of the material across the site; and inconsistency of the construction methodology adopted by the piling contractor.

\subsubsection{Distribution of the Total Load between End Bearing and Skin Friction}

The ratios between the developed end bearing and skin friction $(\beta)$ during the initial stages of loading were estimated using method proposed in Poulos and David [2]. The estimated values of $\beta$ for the case studies are given in Table 1 . There are different factors affecting the value of $\beta$ during initial stages of the loading, such as: stiffness of soil surrounding the pile $\left(E_{s}\right)$; stiffness of material at the pile toe $\left(E_{b}\right)$; length of the pile $(L)$; and diameter $(D)$ of the pile; stiffness of the pile material etc. Due to the effect of large number of parameters on the value of $\beta$, it is very difficult to establish a definite variation of $\beta$ with any single parameter. The variation of $\beta$ with the ratio $E_{b} / E_{s}$ is shown in Figure 5.

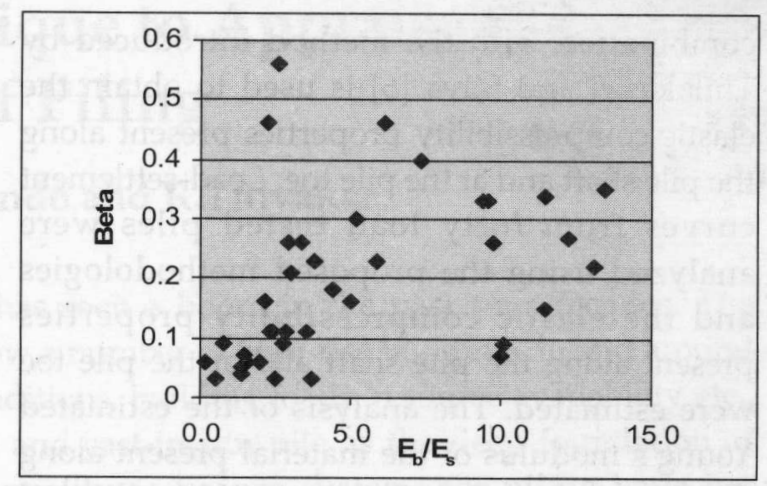

Figure 5: Variation of $\beta$ with $E_{b} / E_{s}$

Figure 5 shows that the variation of $\beta$ is less than about $10 \%$ for the $E_{b} / E_{s}$ ratio less than about 3 . However, it is not possible to establish a definite trend for $\beta$ with $E_{b} / E_{s}$ ratio. The estimated $\beta$ shows that the skin friction is predominant during the initial stage of loading. It also shows that contrary to the common belief among some geotechnical engineers, there is a significant contribution from skin friction to the total load carrying capacity of cast in-situ end bearing bored piles as previously shown by Thilakasiri [4].

\subsection{Conclusions}

The new methodology introduced makes use of the initial stage of the static load-settlement curve to determine the elastic compressibility properties of the material present along the pile shaft. The new method introduced in

Table 3: Typical values of Young's Modulus of soils and rocks from published researches

\begin{tabular}{|c|c|c|c|}
\hline Type of material & $\begin{array}{c}\text { Young's } \\
\text { Modulus } \\
\text { value (MPa) }\end{array}$ & Source & Remarks \\
\hline Medium stiff clay & $8-80$ & Poulos and Davis [2] & Back-figured from piles in clay \\
\hline Stiff clay & $>80$ & Poulos and Davis [2] & Back-figured from piles in clay \\
\hline Loose sand & $27.5-55$ & Poulos and Davis [2] & Suggested for driven pile in sand \\
\hline Medium sand & $55-70$ & Poulos and Davis [2] & Suggested for driven pile in sand \\
\hline Dense sand & $70-110$ & Poulos and Davis [2] & Suggested for driven pile in sand \\
\hline Weathered siltstone & $500-2000$ & Tomlinson[7] & Estimated from plate load test results \\
\hline $\begin{array}{l}\text { Mudstone (strong } \\
\text { moderately weathered and } \\
\text { jointed) }\end{array}$ & 1100 & Tomlinson[7] & Estimated from plate load test results \\
\hline Strong sandstone & 5000 & Tomlinson[7] & Estimated from plate load test results \\
\hline Gneissic Charnockite & $50910-95760$ & Jayawardane [1] & Ultrasonic methods on intact rock samples \\
\hline Hornblende Biotite Gneiss & $37170-48770$ & Jayawardane [1] & Ultrasonic methods on intact rock samples \\
\hline Biotite Gneiss & $31460-58630$ & Jayawardane [1] & Ultrasonic methods on intact rock samples \\
\hline Quartzite & $35960-54170$ & Jayawardane [1] & Ultrasonic methods on intact rock samples \\
\hline Garnet Sillimanite & $49950-73630$ & Jayawardane [1] & Ultrasonic methods on intact rock samples \\
\hline Marble & $48130-65070$ & Jayawardane [1] & Ultrasonic methods on intact rock samples \\
\hline Granulite & $40700-52410$ & Jayawardane [1] & Ultrasonic methods on intact rock samples \\
\hline
\end{tabular}


combination with the method introduced by Thilakasiri and Silva [6] is used to obtain the elastic compressibility properties present along the pile shaft and at the pile toe. Load-settlement curves from forty load tested piles were analyzed using the proposed methodologies and the elastic compressibility properties present along the pile shaft and at the pile toe were estimated. The analysis of the estimated Young's modulus of the material present along the pile shaft and the pile toe clearly showed that the developed methodologies could be used to identify the reason for failure of piles. Furthermore, likely properties of different soil and rock types are also presented to guide the users to identify the likely soil types corresponding to the estimated compressibility properties. Using the elastic material properties estimated, the ratio between the developed end bearing and skin friction ( () for the initial stage of the loading was estimated. Estimated (values show that contrary to the common belief among Sri Lankan geotechnical engineers, there is a significant contribution from skin friction to the total load carrying capacity of cast in-situ end bearing bored piles

\section{Acknowledgement}

Authors would like to express their gratitude to Sierra Construction Ltd, Nawaloka Piling Ltd, Engineering Laboratory Services, Geotech Ltd, State Engineering Corporation (SEC), Buildings Department, Road Development Authority, National Water Supply and Drainage Board, Western Provincial Council, Southern Provincial Council, Ministry of Health and, Atis Piling Ltd for extending their support during this research project.

\section{References}

1. Jayawardane, U. de S., 2001, "A study on the Engineering Properties of Sri Lankan Rocks", Engineer, Institution of Engineers - Sri Lanka, Vol xxxiv, No 02.

2. Poulos, H. G. and Davis, E. H., 1980, Pile Foundation Analysis and Design, 1st edition, John Wiley \& Sons.

3. Poulos, H. G., 1972, Load-Settlement Prediction for Piles and Piers, J. of Soil mech. And Found. Eng., Vol. 98, SM9, pp 879 - 897.

4. Thilakasiri, H. S., 2006, "A Review of the Design Practices of Bored and Cast In-situ Piles in Sri Lanka", Proceedings of Annual sessions of Institution of Engineers, Sri Lanka.

5. Thilakasiri, H. S., Abeyasinghe, R. M., and Tennakoon, B. L., 2006, "Dynamic Testing of End Bearing Bored Piles in Sri Lanka", Proceedings of Annual sessions of Institution of Engineers, Sri Lanka.

6. Thilakasiri, H. S. and Silva, W. H., 2007, "Interpretation of the End Bearing Condition of Bored and Cast In-situ Concrete Piles using Static Pile Load Test Results" accepted for publication in the Proceedings of the Asian Regional Conference of Soil Mechanics and Geotechnical Engineering, Kolkata.

7. Tomlinson, M. J., 1994, Pile Design and Construction Practice, 4th Edition, E \& FN Spon.

8. Van Weele, A. A., 1957, "A Method of Seperating the Bearing Capacity of a Pile into Skin-Friction and Point Resistance", 4th ICSMFE, Vol. 2, pp. 76 